\title{
TWO NEW TROPIDAUCHENIA SPECIES (GASTROPODA: CLAUSILIIDAE: GARNIERIINAE) FROM GUANGXI, CHINA
}

\author{
LU QIU
}

\begin{abstract}
Engineering Research Center for Forest and Grassland Disaster Prevention and Reduction, Mianyang Normal University, Mianxing West Road, 621000, Mianyang, China (e-mail: 123church@163.com); (1) https://orcid.org/0000-0002-0946-1634
\end{abstract}

\begin{abstract}
Tropidauchenia danjuan sp. nov. and T. parasulcicollis sp. nov., both collected in Chongzuo City, Guangxi Province, China, are described and illustrated based on shell characters. T. sulcicollis Grego et Szekeres is re-described based on specimens from Hechi City, Guangxi Province, China.
\end{abstract}

KEY WORDS: taxonomy; new species; door snail; Tropidaucheniini

Publication LSID 5FF2A2C8-85D0-4434-8B34-EFB04D21DDB2

\section{INTRODUCTION}

The subfamily Garnieriinae Boettger, 1926 is mainly distributed through tropical South East Asia, ranging from Myanmar in the west to Vietnam and Southern China in the east (NORDSIECK 2002, 2007). The subfamily is easily distinguished from other Asian Clausiliidae by its furrowed neck, distinctly expanded and unattached peristome, less deeply situated lamellae (except inferior lamella), subcolumellar lamella continuing on the columella inside the shell, in front not shifted toward the palatal wall, and the lunella-type lunellar (NORDSIECK 2007). To date, two tribes, eight genera and more than 50 species of the family have been recorded (NORDSIECK 2007, 2010, 2012, 2016, GREGO et al. 2014).

Guangxi has a typical karstic topography, providing suitable habitats for numerous Clausiliidae, especially for the Garnieriinae. Approximately $83 \%$ of the Chinese garnieriine species have been recorded from Guangxi (NORDSIECK 2012, 2016, GREGO \& SZEKERES 2017). Two genera of this subfamily are found in Guangxi, viz., Tropidauchenia and Grandinenia. The former has the inferior lamella close to, or fused with, the superior lamella, while the latter has the inferior lamella more distant from the superior lamella (NORDSIECK 2012). Grandinenia is diverse at both species and subspecies levels. Its component taxa are mainly distributed in the central and eastern parts of Guangxi, while Tropidauchenia includes only eight species, and its distribution in Guangxi is restricted to the western part (NORDSIECK 2012).

Two new species of Tropidauchenia from Chongzuo, Western Guangxi, are described and illustrated here based on shell characters. T. sulcicollis Grego et Szekeres, 2017, the closest relative of the two new species, is re-described.

\section{MATERIAL AND METHODS}

Photographs were taken using a Canon ${ }^{\circledR}$ EOS RP + Mount Adapter EF-EOS R plus a Laowa ${ }^{\circledR} 100$ mm F2.8 CA-Dreamer Macro $2 \times$ lens (Figs 1-6), or a Leica ${ }^{\circledR}$ M205A stereomicroscope (Figs 7-12). The map was downloaded from d-maps.com. All the figures were modified in Adobe Photoshop ${ }^{\circledR}$ CS6. 
The shell nomenclature follows NORDSIECK (2007) and partly GREGO \& SZEKERES (2017). The studied specimens will be deposited at Mianyang Normal University, Sichuan, China (MYNU).

\section{RESULTS}

\section{Family Clausiliidae Gray, 1855}

\section{Subfamily Garnieriinae Boettger, 1926}

Tribe Tropidaucheniini Nordsieck, 2002

Genus Tropidauchenia Lindholm, 1924

Type species: Garnierina (Tropidauchenia) bavayi Lindholm, 1924.

\section{Tropidauchenia sulcicollis Grego et Szekeres, 2017}

Figs 1, 4, 7, 10

Tropidauchenia sulcicollis GREGO \& SZEKERES 2017: 79, pl. 1, fig. 1 (type locality: "China, Guangxi, Hechi Shi, Duan Xian [=Du'an County都安县]”).

New material examined. 3 dry shells (MYNU 00007-00008), Xiaosanxia [小三峡], Liujia Town [六 甲镇], Jinchengjiang District [金城江区], Hechi City [河池市], Guangxi Province, China, 18.06.2019, LU QIU leg.
Re-description (based on the new material). Shell brown, slender, sinistral and non-decollated, composed of 12 whorls, 18.1-21.5 $\mathrm{mm}$ in height. Pale whitish ribs on the surface fine, dense, and low. On the neck two furrows: one short, around the lunella area, the other long, below the principal plica. Peristome expanded. In frontal view of the aperture, the ends of spiral lamella, superior lamella, principal plica, as well as the auxiliary plica are visible. Anterior lower branch of inferior lamella absent. Inferior lamella completely fused with superior lamella, the end of superior lamella reaches the peristome and is situated next to the spiral lamella in front, while the end of spiral lamella is situated slightly deeper inside the aperture and attached to the superior lamella. Subcolumellar lamella is deeply situated and is only partly visible in oblique view. Principal plica extends from the dorsal side of the neck and almost to the peristome; it end is small and inconspicuous, situated next to the end of spiral lamella; lunella dorso-lat-

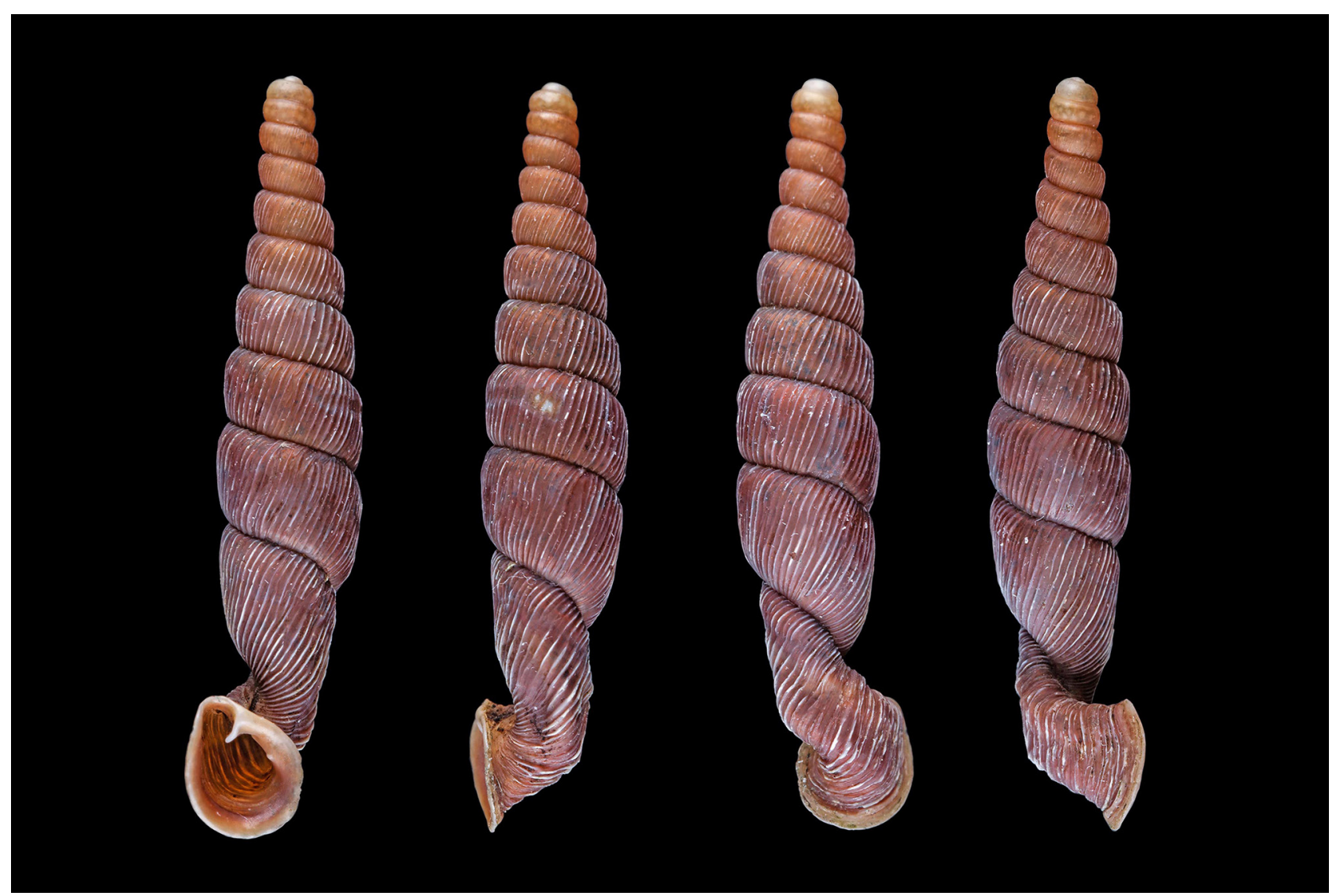

Fig. 1. Shell of Tropidauchenia sulcicollis Grego et Szekeres, 2017, from Xiaosanxia, Hechi, Guangxi, China. Shell height $21.5 \mathrm{~mm}$ 
eral, can only be observed in oblique view. Auxiliary plica present, along the palatal wall under the elongate furrow, sometimes weakly developed (in less mature specimens). Clausilium is partly visible deep in the shell in oblique view.

Distribution. China (Guangxi: Hechi City) (Fig. 14). Habitat. In Xiaosanxia, this species inhabits karst cliffs (Fig. 15).

Remarks. The type locality data are imprecise, it is only stated as Du'an County in Hechi City (GREGO \& SZEKERES 2017). The newly examined specimens were collected in Xiaosanxia, Jinchengjiang District, Hechi City, north of the type locality (Fig. 14).

\section{Tropidauchenia parasulcicollis sp. nov.}

Figs 2, 5, 8, 11, 13

\section{LSID 24AF25DB-4A59-4560-AF08-5162B5718C2A}

Type material. Holotype: MYNU 00005 (dry shell), Guangxi Encheng National Nature Reserve [广西 恩城国家级自然保护区], Daxin County [大新县], Chongzuo Prefecture-level City [崇左市], Guangxi Province, China, 31.03.2021, WEI-DI HUANG leg.; Paratype: MYNU 00006 (1 dry shell), same data as holotype; MYNU 00007-00011 (5 dry shells), same data as holotype, but 25.05. 2021.
Diagnosis. This species resembles $T$. sulcicollis, but differs from it in the stronger, widely spaced ribs on the surface and the absence of auxiliary plica.

Description. Holotype: brown, slender, sinistral and non-decollated shell of 11 whorls covered by distinct whitish ribs, with the edge of aperture slightly whitish and apical part of the shell lighter coloured. The apex is obtuse rounded, the protoconch is comprised of three smooth, non-ribbed whorls. The whorls are separated by a deep suture. The ribs on the surface are strong but low, most of them extending across the whole whorl, evenly distributed and widely spaced, a few of them fading in the neck furrows. On the neck two furrows: one short, around the lunella area, the other long, below the principal plica. Aperture rounded oval, peristome thin, not much expanded, almost as wide as long.

In frontal view of the aperture, the ends of spiral lamella, superior lamella and principal plica are visible. Anterior lower branch of inferior lamella absent. Inferior lamella fully fused with superior lamella, the end of superior lamella reaches the peristome and is situated beside the superior lamella in front, while the end of spiral lamella is located slightly deeper inside the aperture and attached to the superior lamella. Subcolumellar lamella is deeply situated and difficult

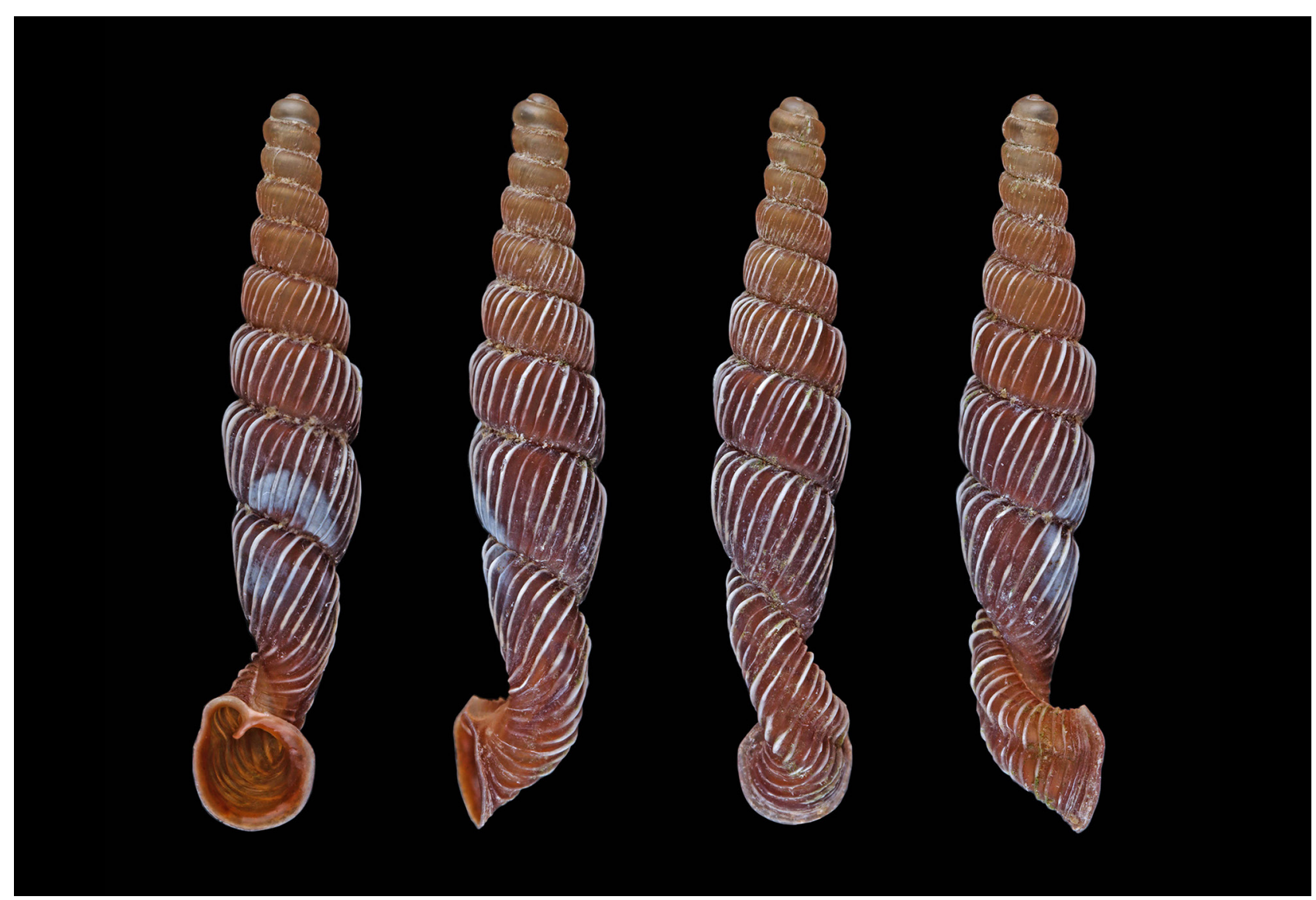

Fig. 2. Shell of Tropidauchenia parasulcicollis sp. nov., holotype MYNU 00005, from Daxin, Chongzuo, Guangxi, China. Shell height $18.2 \mathrm{~mm}$ 
to observe. Principal plica extends from the dorsal side of the neck and almost to the peristome, its end is small, close to the end of spiral lamella; lunella dorso-lateral, it can be seen in oblique view. No auxiliary plica. Clausilium can be partly seen deep inside the shell in oblique view.

Paratypes: similar to holotype, ribs on the surface varied to some extent, but in all the shells they are strong and widely spaced; none of the examined specimens has auxiliary plica.

Measurements [mm]. Holotype: shell height 18.2, shell width 3.4, aperture height 3.1, aperture width 3.1. Paratypes $(n=6)$ : shell height 17.2-19.3, shell width 3.1-3.3, aperture height 2.9-3.0, aperture width 2.9-3.1.

Etymology. The name alludes to the similarity of the new species to T. sulcicollis.

Distribution. China (Guangxi: Chongzuo City) (Fig. 14). Currently known from the type locality only.

Habitat. The species inhabits limestone areas (W.-D. HUANG, personal communication).

Remarks. This species resembles $T$. sulcicollis. The localities of the two species are far apart, and the absence of auxiliary plica, stronger ribs and wider rib intervals make distinction between them easy.

\section{Tropidauchenia danjuan sp. nov.}

Figs 3, 6, 9, 12

LSID DB32C5B1-733B-4329-BC22-16D749742213

Type material. Holotype: MYNU 00001 (dry shell), Ma'an Village [马安村], Taiping Zhen [太平镇], Jiangzhou District [江州区], Chongzuo Prefecturelevel City [崇左市], Guangxi Province, China, 04.2020, WeI-DI HUANG leg.; Paratypes: MYNU 00002-00004 (3 dry shells), same data as holotype.

Diagnosis. The species is characteristic in having fragile and lamelliform ribs on the shell surface. It resembles $T$. sulcicollis and T. parasulcicollis sp. nov., but the shell is yellowish, while in the other two species it is brown; the ribs on the shell surface are lamelliform, thus distinctly higher than in the other two species (solid and low in T. sulcicollis and T. parasulcicollis sp. nov.); T. danjuan sp. nov. is larger (shell height $22.7-24.8 \mathrm{~mm}$ ) than the other two species $(17.2-21.5 \mathrm{~mm})$ based on the examined shells; its peristome is more expanded, a large anterior lower branch of inferior lamella is present, while the other two species have a narrower peristome and no anterior lower branch of inferior lamella.

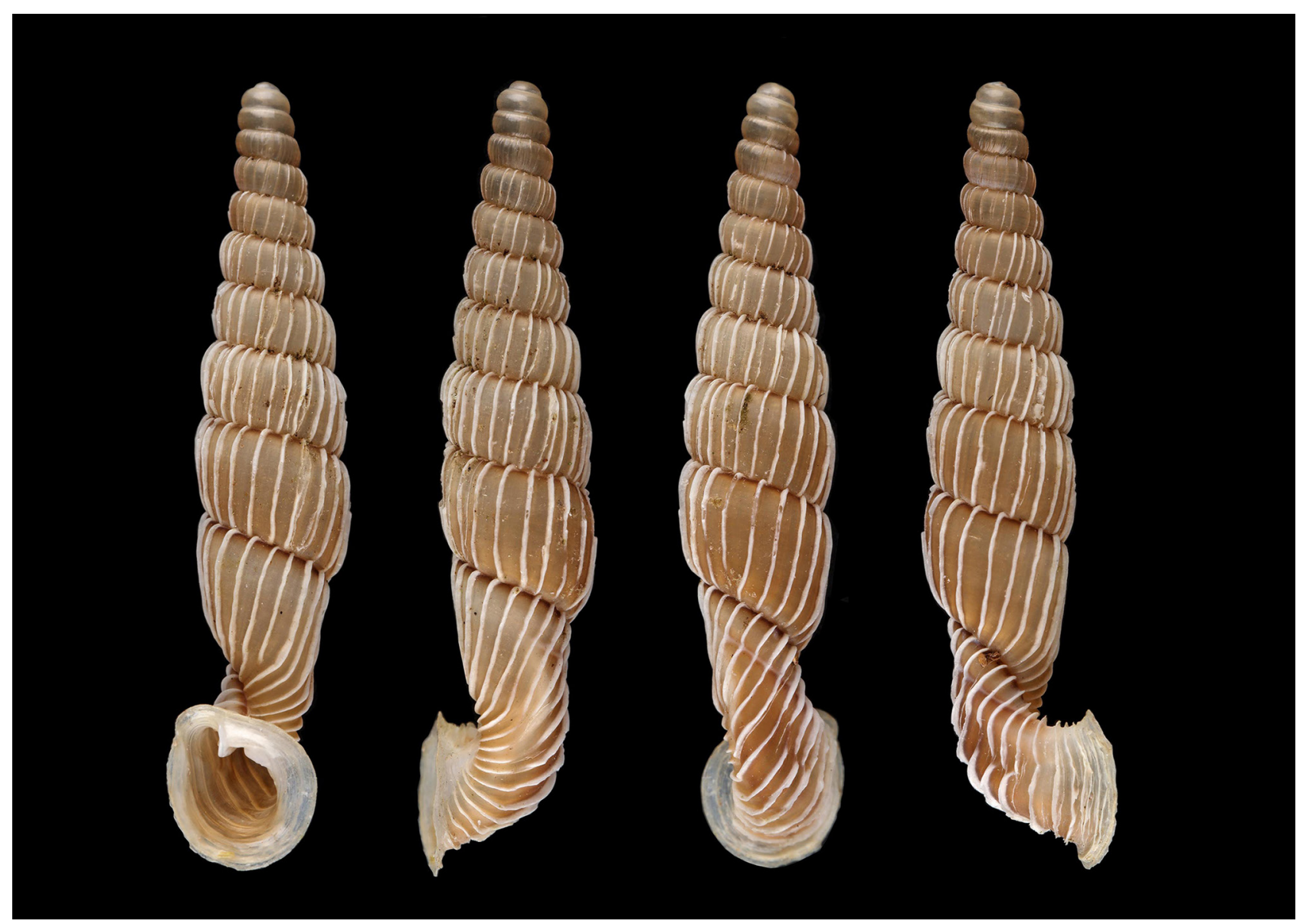

Fig. 3. Shell of Tropidauchenia danjuan sp. nov., holotype MYNU 00001, from Taiping Town, Chongzuo, Guangxi, China. Shell height $23.4 \mathrm{~mm}$ 
Description. Holotype: yellowish, slender, sinistral and non-decollated shell of 12 whorls covered by distinct whitish ribs, with the peristome whitish and the suture faintly reddish brown (except apex). The whorls are separated by a moderately deep suture. The apex is obtuse rounded, the protoconch is comprised of three smooth, non-ribbed whorls. Ribs on the surface lamelliform, fragile, sharp, most of them extending across the whole whorl, rather evenly distributed and widely spaced; they fade in the neck furrows. On the neck two long furrows, one around the lunella area, the other below the principal plica. Aperture rounded oval, higher than wide; peristome thin, somewhat expanded.

In frontal view of the aperture, the anterior lower branch of inferior lamella, the ends of spiral lamella, superior lamella and principal plica are visible. Inferior lamella fully fused with the superior lamel- la, the end of superior lamella reaches the peristome and is situated beside the spiral lamella in front, while the end of the spiral lamella is situated slightly deeper inside the aperture and looks somewhat like a continuation of the superior lamella. Subcolumellar lamella is deeply situated and its end is visible in oblique view. Principal plica extends from the dorsal side of the neck and almost to the peristome; its end is small, located next to the end of the spiral lamella, but slightly deeper inside; lunella dorso-lateral, it can be observed in oblique view. No auxiliary plica. Clausilium can be partly seen in oblique view.

Paratypes: similar to holotype, but slightly varying in shell height and width, aperture size, and the degree of development of the apertural barriers.

Measurements [mm]. Holotype: shell height 23.4, shell width 4.3 , aperture height 4.8 , aperture width 4.2 .
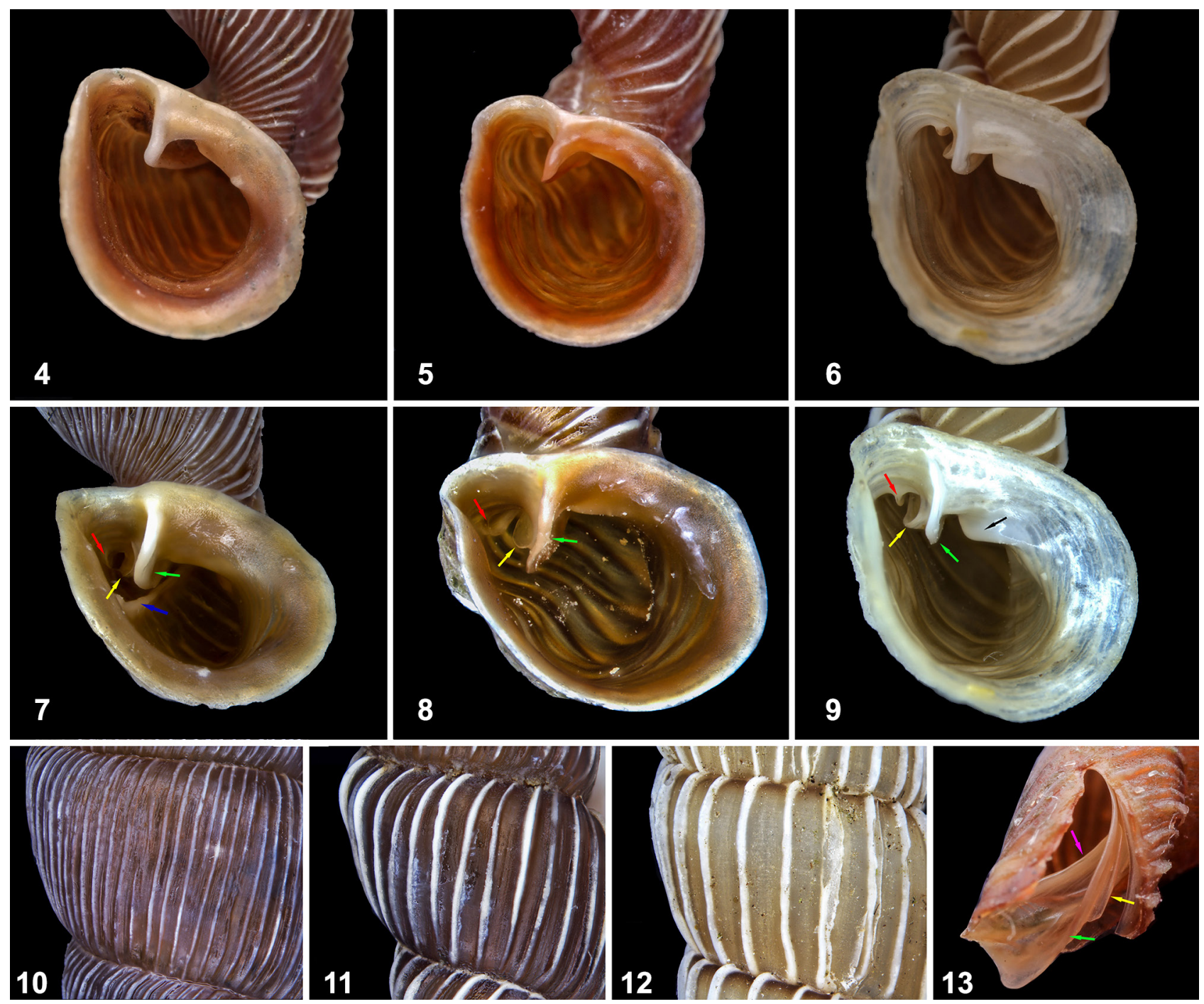

Figs 4-13. Shell characters of Tropidauchenia spp.: 4-6 - aperture, frontal view; 7-9 - aperture, oblique view; 10-12 - ribs on shell surface; 13 - lamella structures; 4, 7, 10 - T. sulcicollis; 5, 8, 11, 13 - T. parasulcicollis sp. nov.; 6, 9, 12 - T. danjuan sp. nov.; colour arrows in 7-9 and 13 indicate: red - principal plica; yellow - spiral lamella; green - superior lamella (inferior lamella fully fused with it); black (9) - anterior lower branch of inferior lamella; blue (7) - auxiliary plica; purple (13) - subcolumellar lamella 


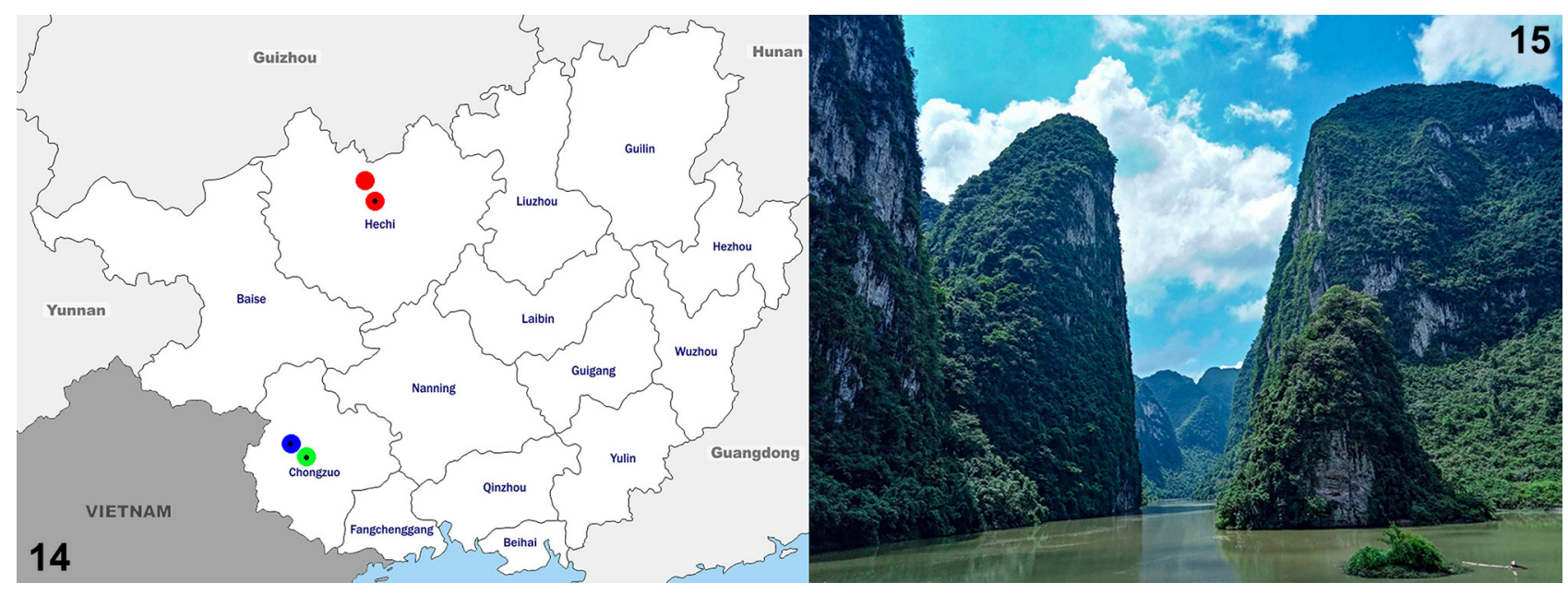

Figs 14-15. Distribution map and habitat of Tropidauchenia spp.: 14 - distribution map of the three species in Guangxi (red circle: T. sulcicollis, blue circle: T. parasulcicollis sp. nov., green circle: T. danjuan sp. nov.; circles with black dots indicate type localities); 15 - habitat of T. sulcicollis, Xiaosanxia, Hechi, Guangxi, China. Photo: L. QIU (taken in June 2019)

Paratypes $(\mathrm{n}=3)$ : shell height $22.7-24.8$, shell width 3.8-4.2, aperture height 4.2-4.5, aperture width 3.4-4.1. Etymology. "Danjuan" [蛋卷] is the Chinese word for Barquillo. The shell appearance and its fragility remind me of this dessert.

Distribution. China (Guangxi: Chongzuo City) (Fig. 14). Currently known from the type locality only.

Habitat. The species inhabits limestone areas (W.-D. HUANG, personal communication).

\section{ACKNOWLEDGEMENTS}

I thank Mr. ZHENG-PING LIU (Chengdu, China) for introducing me to the land snail world, sharing his extensive knowledge and experience and encouraging me. I am grateful to ZHE-YU CHEN (Wuhan, China), KAI-CHEN OUYANG (Wuhan, China), DE-YAO ZHOU (Shanghai, China), RAN-XI LIN (Guangzhou, China), YONG-HENG ZHU (Dongguan, China) for sharing their knowledge of snails, and to WEI-DI HUANG (Chongzuo, China) who collected the specimens. My thanks go to the editor and two anonymous reviewers for their critical remarks. I was inspired by some bad taxonomic papers which induced me to study snails rather than collecting them for fun. The study was supported by the Happy Snail Collecting Fund [No. 01231991].

\section{REFERENCES}

BOETTGER C. R. 1926. Systematic and geographical notes on Clausiliidae. Archiv für Naturgeschichte Berlin 91: $1-18$.

GRAY J. E. 1855. Catalogue of Pulmonata or air-breathing Mollusca in the collection of the British Museum, Part I. Order of the Trustees, London.

Grego J., Luong H. V., Pham S., Szekeres M. 2014. Vietnamese Clausiliidae (Gastropoda: Pulmonata): new taxa and novel distribution data. Journal of Conchology 41: 749-757.

Grego J., SzeKeres M. 2017. New Clausiliidae (Mollusca: Gastropoda) from China. Visaya 4: 79-93.

LINDHOLM W. A. 1924. A revised systematic list of the genera of the Clausiliidae, recent and fossil, with their subdivisions, synonymy and types. Proceedings of the Malacological Society of London 16: 53-80.

NORDSIECK H. 2002. Revision of the Garnieriinae (Gastropoda: Stylommatophora: Clausiliidae), with

descriptions of new taxa. Stuttgarter Beiträge zur Naturkunde, Serie A (Biologie) 640: 1-23.

NordsIECK H. 2007. Worldwide Door Snails (Clausiliidae), recent and fossil. ConchBooks, Germany.

NordsiECK H. 2010. New taxa of the subfamilies Neniinae and Garnieriinae (Gastropoda: Stylommatophora: Clausiliidae). Archiv für Molluskenkunde 139: 45-69. https://doi.org/10.1127/arch.moll/1869-0963/139/045-069

NordsieCK H. 2012. Clausiliidae of Guangxi, southern China (Gastropoda, Pulmonata, Stylommatophora). Acta Conchyliorum 12: 3-56.

NorDSIECK H. 2016. New species taxa of Clausiliidae (Gastropoda, Stylommatophora) from China and Vietnam. Conchylia 47: 37-57. 